\title{
Important information for the selection of workplace canteen meals: A consumer segmentation study
}

\author{
S. Price ${ }^{1}$, K.M. Appleton ${ }^{1}$, J. Bray ${ }^{1}$, A. Giboreau ${ }^{2}$, F.J.A. Perez-Cueto ${ }^{3}$, I. Mavridis ${ }^{4}$, M. Ronge ${ }^{5}$ \\ and H. Hartwell ${ }^{1}$ \\ ${ }^{1}$ Bournemouth University, Poole, UK, ${ }^{2}$ Institut Paul Bocuse, Ecully, France, ${ }^{3}$ University of Copenhagen, Copenhagen, \\ Denmark, ${ }^{4}$ University of Macedonia, Thessalonika, Greece and ${ }^{5}$ Ronge \& Partners, Baden, Austria
}

The provision of nutritional information has been associated with improved intakes and dietary profiles ${ }^{(1,2)}$, but in a workplace canteen, consumers typically have very little information on the foods they are eating ${ }^{(3)}$. Importantly, furthermore, provided information is more likely to be used and valued, if consumers consider it to be relevant to them ${ }^{(2,3)}$. This study aimed to characterize consumers based on the information of importance to them when selecting a meal from a workplace/university canteen.

Using an online questionnaire, 452 individuals with access to a workplace/university canteen, from Denmark, France, Greece and the UK, were asked to choose the information of importance to them in meal selection, using a best-worst scaling method. Options for information provision were based on earlier work that identified eight factors of potential importance to meal selection in a workplace canteen on which information could be provided - 'value for money', 'naturalness', 'nutrition', 'origin', 'animal welfare', 'environmental impact', 'fair trade' and 'organic'. Important factors were identified per individual (as best-worst utility scores) and these data were analysed by latent class cluster analysis.

In general, and across countries, information on 'value for money', 'nutrition' and 'naturalness' was most important to consumers. Latent class cluster analysis was performed and a five cluster solution chosen as best fit $(\mathrm{BIC}=16900 \cdot 8$, error $=0 \cdot 11)$. Thereby, five clusters of consumers were identified, characterised as:

- 'value driven' (33\% of sample) - high importance of 'value for money', and to some extent of 'nutrition' and 'naturalness', but low importance of environmental concerns

- 'conventionalist' (23.2\% of sample) - high importance of 'value for money' and 'nutrition', and some consideration also of more socially conscious factors

- 'socially responsible' ( $19.2 \%$ of sample) - high importance of the factors involved in food production 'environmental impact', 'fair trade', 'organic' and 'animal welfare', low importance of 'value for money' 'nutrition' and 'naturalness'

- 'health conscious' ( $14.2 \%$ of sample) - high importance of 'naturalness', 'organic' and 'nutrition', low importance of 'value for money' and of more environmental and socially conscious factors

- 'locavores' (10.4\% of sample) - high importance of 'provenance', and to some extent of 'environmental impact' and 'naturalness', low importance of 'nutrition'

Cluster membership varied dependent on country, demographic and employment details.

These findings suggest different information to be more/less important to different consumers when selecting a workplace canteen meal. Provision of only the information important to an individual may result in increased use and value of that information, as previously demonstrated $^{(2,3)}$. Marie Curie EU-funded project FoodSMART aims to develop an interactive mobile phone application to provide this personally important information.

1. Vanderlee L, Hammond D. Does nutrition information on menus impact food choice? Comparisons across two hospital cafeterias. Public Health Nutr. 2014, 17, 1393-402.

2. Brinberg D, Axelson ML, Price S. Changing food knowledge, food choice, and dietary fiber consumption by using tailored messages. Appetite $2000,35,35-43$.

3. Bohm E, Quartuccio N. Healthy dining restaurant nutrition program - a winning recipe for consumers, dietitians and restaurants. J Am Diet Assoc, 2008,108, A 112 . 